\title{
Integrated pest management at the crossroads: Science, politics, or business (as usual)?
}

\author{
Heikki M. T. Hokkanen ${ }^{1}$
}

Published online: 23 October 2015

(C) Springer Science+Business Media Dordrecht 2015

\section{The era of 'IPM?'}

Integrated pest management (IPM) arose as a solution to problems associated with the indiscriminate use of chemical pesticides to control pests, diseases and weeds, more than 50 years ago. Elegant solutions have been found to the majority of problems, based on meticulous scientific work and discoveries related to pest (sensu lato) biological properties, ecology, ecosystem function, and technological innovations. Uptake of these methods and application by growers has lagged far behind, despite ambitious government programmes to reduce pesticide use, and political support to IPM. The European Union has taken this support to a new level by passing a directive (2009/128/EC), which effectively requires Member States to ensure that all professional growers follow the principles of IPM, as of 1 January 2014. Are we finally adopting the principles of IPM in plant protection?

\section{Reality gap in IPM}

The current reality does not generate confidence, if we consider the gap between the traditional IPM principles, as expressed in the "IPM pyramid", and the actual situation in mainstream pest management (Fig. 1). Ideally, pest management is based to a large extent on avoidance, and the use of chemical pesticides is just a small tip of the pyramid.

Heikki M. T. Hokkanen

heikki.hokkanen@helsinki.fi

1 Department of Agricultural Sciences, University of Helsinki, Box 27, 00014 Helsinki, Finland
In current reality the pyramid is upside down, where most of the actual pest management is conducted through the use of chemical pesticides. It becomes obvious that this method of pest management will neither be stable nor sustainable.

\section{Science}

Will science help to close the reality gap, and facilitate adoption of effective IPM throughout all crops, concerning their major pests, diseases and weeds? It is clear that only science can provide the information needed to close the gap, but the real question is whether there are the resources available to conduct all the research needed to support the transition to IPM. An example of research needs is the requirement for scientifically sound economic thresholds for pests; this is critical to both implementing IPM and for use by any decision support system to help growers assess whether control measures are needed. Practically all existing thresholds have been established decades agomost in the 1970s-while currently, we have completely different crop varieties, cropping systems and technology, and commodity prices.

In today's competitive funding situation for a vast majority of researchers, it is difficult to believe that grant applications addressing establishment of economic thresholds would be successful at any funding agency. Scientists wishing to pursue an academic career will not be easily promoted if their major publications focus on establishing valid economic thresholds for IPM. Academic excellence requires innovations and advances in theories and understanding of fundamental biological and ecological mechanisms. Scientific discoveries are needed for advancing IPM, but clearly are not sufficient for establishing IPM in the field. 

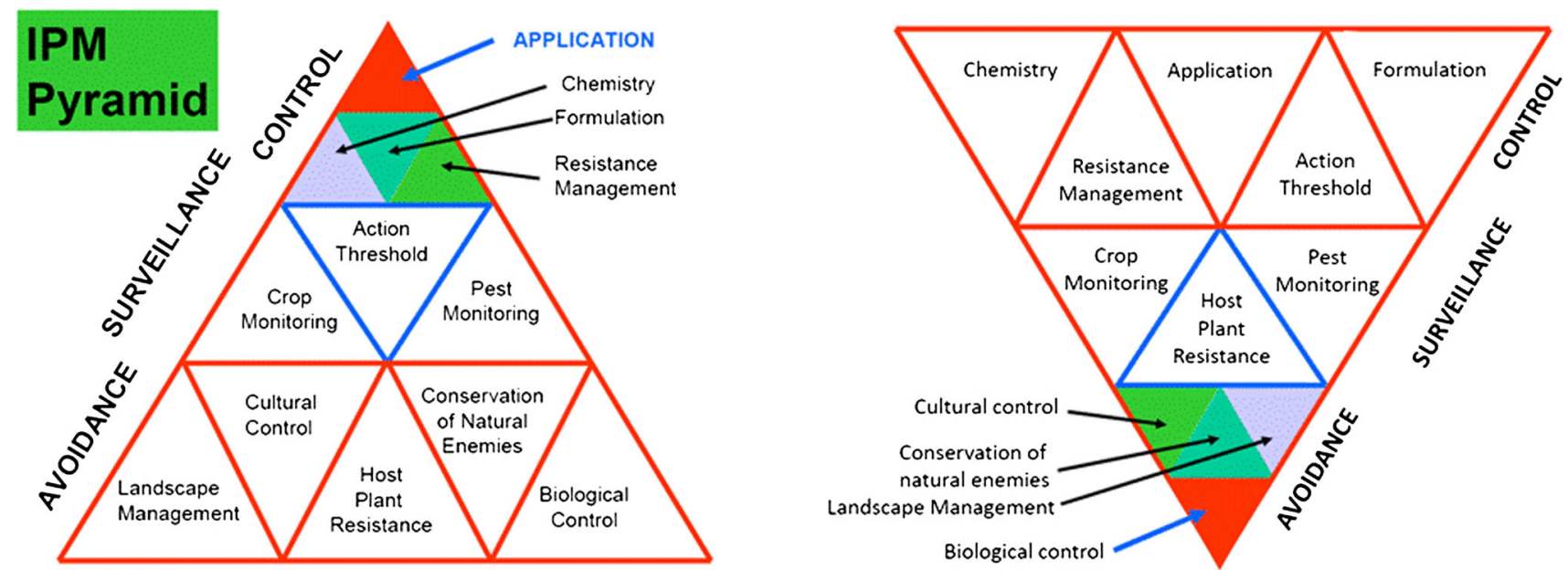

Fig. 1 The "reality gap" in pest management: ideal IPM as promoted for $>50$ years (left), and current reality in mainstream pest management (right)

\section{Politics}

Although the political 'macro'-climate has become favourable to IPM at least in some parts of the world, other political interests may swamp the efforts to make IPM work, or even prevent the first steps towards IPM. A case in point might be the temporary ban on some neonicotinoids in the EU. While the ban was established for the growing seasons of 2014 and 2015, in several countries (e.g., Finland) in both years growers were allowed to use neonicotinoid seed dressing in rapeseed growing via emergency exemption (McGrath 2014). Another example: politics restrict the choices of potential IPM tools, such as growing genetically modified (GM) crops in most European countries.

\section{Business (as usual)}

As a rule, growers are hard pressed by economic and business realities, and seldom have a real choice in selecting the pest management options. That IPM is not taken up by growers to a larger extent is usually not their own choice, but a decision dictated by the markets within the existing legal frame-imposed by politics and in the end, the society at large. A clear example of 'business as usual' are the GM crops, and the way they have been handled. GM crops have been taken up by growers at a phenomenal rate, with about $70-80 \%$ of global plantings of some main crops (soya, cotton) being GM (James 2014). The promise of the first generation GM crops has been to provide (1) more efficient pest, disease and weed control, (2) lower use of pesticides, (3) improved biological control, and (4) improved possibility for IPM. Theoretically, most
GM crops and their new traits have the potential to significantly improve crop production especially under heavy pest, disease and weed pressure, and as part of an IPM programme. In consideration of the bigger picture, the reality is different: Herbicide-resistant crop technology led to a 239 million $\mathrm{kg}$ increase in herbicide use in the USA between 1996 and 2011, while Bt crops have reduced insecticide applications by 56 million $\mathrm{kg}$ (Benbrook 2012). Overall, pesticide use in the first 15 years of commercial use increased by an estimated 183 million $\mathrm{kg}$, or about $7 \%$.

Two major traits of importance for IPM have been commercialized so far: insect resistance and herbicide tolerance. A number of reviews (e.g., Lundgren et al. 2009) have shown that insect resistance in GM crops (1) dramatically reduces pesticide inputs, (2) improves biological control of other pests (3) conserves pollination services, and (4) improves crop productivity under high target pest pressure. On the other hand, herbicide tolerance (1) usually increases pesticide inputs (herbicides), (2) interferes with biocontrol and pollination by removing nectar and pollen resources, but (3) improves crop productivity under high weed pressure.

In reality, the theoretical benefits of pest and diseaseresistant GM crops seldom seem to be achieved. GM crops are as a rule seen by the growers as a stand-alone technology for pest and disease control, without any real attempts to integrate them as a component in IPM. In this situation, their fate will be the same as that of chemical pesticides: unstable and unsustainable crop protection (cf. Fig. 1).

There are already severe signs that this is happening. For example, herbicide-resistant weeds have arisen at an accelerating rate, and it is a paradox that growers of 
herbicide tolerant cotton have had to resort to hand weeding: Amaranthus palmeri needs to be hand weeded in HT cotton systems in the USA. Hand weeding in HT cotton was in 2000-2005 practised by $17 \%$ of growers on a total of $5 \%$ cotton acres in the USA at the cost of $\$ 2.40 / \mathrm{A}$, while in 2006-2010, $92 \%$ of growers hand-weeded $52 \%$ cotton acres, at the cost of \$23.70/A (Culpeper 2015). Similarly, Tabashnik et al. (2013) have shown how the first reports of field evolved resistance to $\mathrm{Bt}$ crops in Lepidoptera appeared 10 years after commercial cultivation of these crops, and more species have been added to that list annually, such that in 2011, at least six different species had reduced sensitivity to Bt crops around the world. It should be noted, however, that the main target pest of Btmaize, the European corn borer Ostrinia nubilalis, still has not shown reduced sensitivity to Bt-maize, anywhere-all reported cases refer to secondary target pests on maize. In Bt-cotton the situation is different, as the main target species are among those with reported reduced sensitivity.

GM crops are currently grown over 180 million ha, on all continents-but where is the IPM? It is possibly illustrative that at the recent conference, the 8th International IPM Symposium (IPM: Solutions for a Changing World, March 23-26, 2015 in Salt Lake City, Utah, USA), only two out of 47 separate Symposia dealt specifically with GM crops. These focussed solely on the problematics of herbicide tolerant weeds and did not actually place them in an IPM context, either. Therefore, in the USA and internationally, GM crops do not seem to be an issue in the discussions on IPM, nor are the crops put into IPM context even at scientific conferences. Business as usual-without IPM.
Arthropod-Plant Interactions covers many critical topic areas for the development of IPM, ranging from pure science including GM and molecular approaches, to practical applications. We welcome submissions on all of these aspects dealing with interactions between arthropods and plants. Solid science is the only way to successful IPM, and we at APIS want to promote that as much as possible (e.g., Ferrater et al. 2013; Paudel et al. 2014, Timm and Reineke 2014).

\section{References}

Benbrook CM (2012) Impacts of genetically engineered crops on pesticide use in the US- the first sixteen years. Environ Sci Eur 24:24

Culpeper S (2015) Presentation at the 8th international IPM symposium (IPM: solutions for a changing world) March 23-26, 2015 Salt Lake City, Utah, USA

Ferrater JB, de Jong PW, Dicke M, Chen YH, Horgan FG (2013) Symbiont-mediated adaptation by planthoppers and leafhoppers to resistant rice varieties. Arthropod Plant Interact 7:591-605

James C (2014) Global status of commercialized biotech/GM crops. ISAAA Brief No. 49. ISAAA, Ithaca

Lundgren JG, Gassmann AJ, Bernal J, Duan JJ, Ruberson J (2009) Ecological compatibility of GM crops and biological control. Crop Prot 28:1017-1030

McGrath PF (2014) Politics meets science: the case of neonicotinoid insecticides in Europe. S.A.P.I.EN.S 7.1, Online since 01 July 2014, connection on 17 October 2015. http://sapiens.revues.org/1648

Paudel S, Rajotte EG, Felton GW (2014) Benefits and costs of tomato seed treatment with plant defense elicitors for insect resistance. Arthropod Plant Interact 8:539-545

Tabashnik BE, Brévault T, Carrière Y (2013) Insect resistance to Bt crops: lessons from the first billion acres. Nat Biotechnol 31:510-521

Timm AE, Reineke A (2014) First insights into grapevine transcriptional responses as a result of vine mealybug Planococcus ficus feeding. Arthropod Plant Interact 8:495-505 